\title{
PENGARUH GAYA KEPEMIMPINAN, EFEKTIVITAS ORGANISASI DAN GAYA NEGOSIASI TERHADAP INOVASI PRODUK UMKM HIJAB DI KABUPATEN BEKASI
}

\section{Junedi, Adibah Yahya, Diana Sari}

Universitas Pelita Bangsa Bekasi, Indonesia

Email: junedi@pelitabangsa.ac.id, adibah.yahya@pelitabangsa.ac.id diana.sari.bil@gmail.com

\begin{abstract}
Abstrak
Fenomena busana hijab menjadi suatu fashion style di kalangan masyarakat Muslim di Indonesia, menuntut produsen melakukan inovasi produk sesuai kebutuhan yang fashionable dan modern. Penelitian ini merupakan penelitian kuantitatif dengan data primer dan data sekunder, sampel yang digunakan sebanyak 30 pelaku usaha. Metode pengumpulan data menggunakan angket dan observasi yang kemudian hasilnya di uji menggunakan Statistical Package for the Social Sciences (SPSS) melalui uji validitas, uji reliabilitas, uji asumsi klasik serta analisis regresi berganda. Hasil penelitian yang dilakukan menunjukkan bahwa variabel gaya kepemimpinan, efektivitas organisasi dan gaya negosiasi mempunyai pengaruh positif dan signifikan terhadap inovasi produk UMKM hijab di Kabupaten Bekasi.
\end{abstract}

Kata Kunci: inovasi produk; fashion hijab; UMKM

\section{Abstract}

The phenomenon of hijab fashion becoming a fashion style among the Muslim community in Indonesia, requires manufacturers to innovate products according to fashionable and modern needs. This research is a quantitative research with primary data and secondary data, the sample used is 30 business actors. Methods of data collection using questionnaires and observations which then the results are tested using the Statistical Package for the Social Sciences (SPSS) through validity tests, reliability tests, classical assumption tests and multiple regression analysis. The results of the research conducted indicate that the variables of leadership style, organizational effectiveness and negotiation style have a positive and significant influence on product innovation of hijab SMEs in Bekasi Distric.

Keywords: product innovation; hijab fashion; SMEs

Received: 2021-11-20; Accepted: 2021-12-05; Published: 2021-12-20

$\begin{array}{ll}\text { How to cite: } & \text { Junedi, Adibah Yahya \& Diana Sari (2021). Pengaruh Gaya Kepemimpinan, Efektivitas Organisasi dan Gaya } \\ & \text { Negosiasi Terhadap Inovasi Produk UMKM Hijab di Kabupaten Bekasi. Syntax Literate: Jurnal Ilmiah } \\ & \text { Indonesia, 6(12). http://dx.doi.org/10.36418/ Syntax-Literate.v6i12.5046 } \\ \text { E-ISSN: } & \text { 2548-1398 } \\ \text { Published by: } & \text { Ridwan Institute }\end{array}$




\section{Pendahuluan}

Kehadiran fashion hijab dalam dunia fashion wanita Muslimah menjadi fenomena kapitalisasi hijab dari komoditas keagamaan menjadi sarana ekspresi gaya hidup. Fashion dapat didefinisikan dengan berbagai cara dapat dilihat tergantung aspek mana dari fenomena itu ditekankan (Indrianti, Kurniawan, \& Hassan, 2021). Adanya fenomena pasar tersebut, membuat produsen industri hijab di Indonesia menyuguhkan berbagai style fashion hijab dengan menciptakan ciri khas masing-masing dari merk produknya (Hassan \& Harun, 2016).

Inovasi merupakan langkah perusahaan untuk terlibat dan mendukung kebaruan, ide-ide baru, kreatif proses dan eksperimen yang mengarah pada produk baru atau proses teknologi baru (Fitriati, Purwana, \& Buchdadi, 2020). Inovasi produk perlu dilakukan bagi pengusaha fashion hijab dalam menghadapi persaingan agar memberikan pilihan produk bagi pelanggan. Untuk mewujudkan hal tersebut maka perlu adanya kajian variabel apa saja yang dapat membentuk terwujudnya inovasi produk melalui pendekatan kajian: 1). Gaya kepemimpinan, berdasarkan pengamatan di lapangan masih banyak dijumpai unit usaha masih dikelola secara konvensional yang belum menggunakan peran kepemimpinan dalam menjalankan usahanya. Gaya kepemimpinan memberikan dampak pada pengetahuan dan keterampilan yang substansial (Colovic, 2021). Kepemimpinan memainkan peranan penting dalam mendorong hasil kegiatan inovasi dalam organisasi (Oke, Munshi, \& Walumbwa, 2009). 2). Efektivitas organisasi memberikan bukti bahwa kapasitas inovasi dipengaruhi karakteristik organisasi (Kurniati, 2014). Unit usaha UMKM perlu membuat organisasinya lebih proaktif dan kreatif agar terus mempromosikan ide baru yang inovatif (Gomes, Seman, Berndt, \& Bogoni, 2021), Dalam kondisi perubahan lingkungan yang dinamis, organisasi membutuhkan kapasitas manajerial untuk berpikir dan bertindak strategis (Temouri, Shen, Pereira, \& Xie, 2020). 3). Gaya negosiasi merupakan pendekatan kompetitif dalam negosiasi, di mana para pemimpin usaha kecil terlibat memanfaatkan sumber daya mereka yang terbatas untuk inovasi lebih baik (Dunne, Aaron, McDowell, Urban, \& Geho, 2016). Keberhasilan negosiasi memberikan efektivitas tercapai tujuan organisasi (Peleckis, 2014).

Dengan memperhatikan peran inovasi produk tersebut, maka penelitian ini bertujuan untuk menganalisis pengaruh gaya kepemimpinan, efektifitas organisasi dan gaya negosiasi terhadap inovasi produk umkm fashion hijab di Kabupaten Bekasi.

\section{Metode Penelitian}

Pada penelitian ini menggunakan pendekatan kuantitatif yang dilakukan pada kelompok pemilik usaha fashion hijab di Kabupaten Bekasi. Pengumpulan data dilakukan melalui kuesioner untuk mendapatkan jawaban dari responden dengan memberikan pertanyaan yang telah disiapkan agar mendapat jawaban responden yang valid sebagia data. Konsep penelitian ini yaitu Inovasi Produk (IP) merupakan variabel dependen, sedangkan Gaya Kepemimpinan (GK), Efektifitas Organisasi (EO) dan Gaya 
Negosiasi (GN) merupakan variabel independen. Dengan desain penelitian yang dapat dilihat pada bagan sebagai berikut:

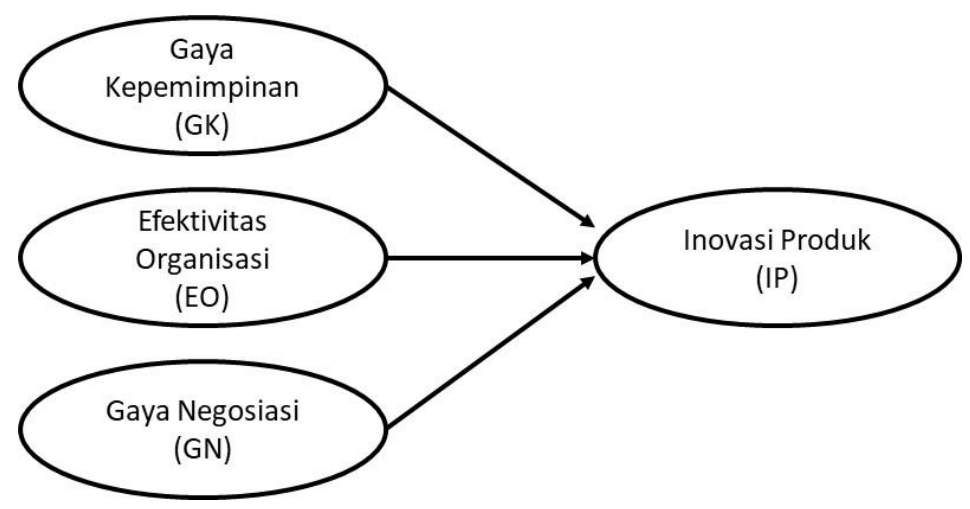

\section{Gambar 1 \\ Desain Penelitian}

Dalam penelitian ini melibatkan 30 pemilik usaha fashion hijab di Kabupaten Bekasi, untuk mengisi jawaban yang telah disediakan menggunakan skala likert 1-5, dengan kriteria 1 sangat tidak setuju dan 5 sangat setuju. Penaksiran ini untuk mendapatkan verifikasi dalam bentuk dukungan empiris data dilapangan, karena data yang disajikan berupa angka dan menggunakan analisis statistik(Memon et al., 2020), selanjutnya data di analisa : 1) uji validitas dan realibilitas, 2). uji asumsi, 3). uji model dan 4). uji hipotesis.

Tabel 1

Operasionalisasi Variabel

\begin{tabular}{llc}
\hline \multicolumn{1}{c}{ Variabel/ Konsep } & \multicolumn{1}{c}{ Indikator } & Skala \\
\hline & IP.1 Produk baru bagi dunia & \\
& IP.2 Lini produk baru & Interval \\
Inovasi Produk (IP) & IP.3 Tambahan pada lini produk. & $1-5$ \\
& IP.4 Perbaikan dan revisi produk & \\
& IP.5 Penentuan kembali & \\
\hline Gaya Kepemimpinan (GK) & GK.1 Kepemimpinan Otokratis & Interval \\
& GK.2 Kepemimpinan Partisipatif & $1-5$ \\
& GK.3 Kpemimpinan kendali bebas & \\
& EO.1 Produktivitas tinggi & Interval \\
Efektivitas Organisasi (EO) & EO.2 Efisien & \\
& EO.3 Memperoleh sumber daya & \\
& EO.4 Perencanaan yang matang & \\
& EO.5 Kondisi stabil & \\
& EO.6 Ketersediaan Informasi & \\
& EO.7 Kohesivitas karyawan solid & \\
\hline
\end{tabular}




\begin{tabular}{llc}
\hline & GN.1 Kemampuan Bersaing & \\
& GN.2 Menghindari konflik & Interval \\
Gaya Negosiasi (GN) & GN.3 Melakukan kolaborasi & $1-5$ \\
& GN.4 Kemampuan mengakomodasi & \\
& GN.5 Taktik berkompromi & \\
\hline
\end{tabular}

Sumber: Rangkuman teori, 2021

\section{Hasil dan Pembahasan}

\section{A. Analisis uji instrumen yaitu validitas dan reliabilitas)}

Jika r-hitung > r-tabel maka kuesioner tersebut dianggap valid sebaliknya jika r-hitung < r-tabel kuisioner dinyatakan tidak sah. R-tabel dengan jumlah responden $\mathrm{N}=30$ pada tingkat signifikansi $5 \%$ adalah 0.361 . Uji reliabilitas untuk mengetahui konsistensi kuisioner yang digunakan sehingga kuisioner dapat gunakan. Uji Reabilitas yang digunakan yaitu dengan teknik Cronbach's Alpha dimana variabel dikatan reliabel jika nilainya $>0.600$.

Tabel 2

Validitas -Realibilitas

\begin{tabular}{lccc}
\hline $\begin{array}{c}\text { Variabel; } \\
\text { Indikator }\end{array}$ & Cronbach's; r-hitung & Nilai Kritis & Keterangan \\
\hline Inovasi Produk (IP) & 0,773 & 0,600 & Reliabel \\
IP.1 Produk baru bagi dunia & 0,756 & 0,361 & Valid \\
IP.2 Lini produk baru & 0,839 & 0,361 & Valid \\
IP.3 Tambahan pada lini produk. & 0,743 & 0,361 & Valid \\
IP.4 Perbaikan dan revisi produk & 0,677 & 0,361 & Valid \\
IP.5 Penentuan kembali & 0,698 & 0,361 & Valid \\
\hline Gaya Kepemimpinan (GK) & 0,653 & 0,600 & Reliabel \\
GK.1 Kepemimpinan Otokratis & 0,862 & 0,361 & Valid \\
GK.2 Kepemimpinan Partisipatif & 0,553 & 0,361 & Valid \\
GK.3 Kpemimpinan kendali bebas & 0,860 & 0,361 & Valid \\
\hline Efektivitas Organisasi (EO) & 0,866 & 0,600 & Reliabel \\
EO.1 Produktivitas tinggi & 0,772 & 0,361 & Valid \\
EO.2 Efisien & 0,791 & 0,361 & Valid \\
EO.3 Memperoleh sumber daya & 0,715 & 0,361 & Valid \\
EO.4 Perencanaan yang matang & 0,757 & 0,361 & Valid \\
EO.5 Kondisi stabil & 0,773 & 0,361 & Valid \\
EO.6 Ketersediaan Informasi & 0,616 & 0,361 & Valid \\
EO.7 Kohesivitas karyawan solid & 0,792 & 0,361 & Valid \\
\hline Gaya Negosiasi (GN) & 0,790 & 0,600 & Reliabel \\
GN.1 Kemampuan Bersaing & 0,787 & 0,361 & Valid \\
GN.2 Menghindari konflik & 0,791 & 0,361 & Valid \\
GN.3 Melakukan kolaborasi & 0,663 & 0,361 & Valid \\
GN.4 Kemampuan mengakomodasi & 0,858 & 0,361 & Valid \\
GN.5 Taktik berkompromi & 0,590 & 0,361 & Valid \\
\hline
\end{tabular}

Sumber: Data penelitian diolah, 2021 


\section{B. Analisis uji asumsi sebagai bentuk persyaratan analisis regresi linier ganda}

Asumsi pertama yaitu normalitas untuk memastikan data pada tabel adalah benar teruji normal dengan menguji variabel residu dengan kriteria sig (signifikansi) $>0.05$, maka data berdistribusi secara normal. Asumsi kedua multikolinieritas yang digunakan untuk memastikan ada tidaknya korelasi antar variabel bebas (independent) dengan kriteria nilai tolerance mendekati 1 dan atau VIF kurang dari 10. Asumsi ketiga heterokedastisitas yaitu menguji perbedaan variance nilai residual antar periode pengamatan dengan kriteria test statistik atau Sig $>0.05$.

\section{Tabel 3}

Ringkasan Hasil Uji Asumsi

\begin{tabular}{lcccc}
\hline \multicolumn{1}{c}{ Komponen Variabel } & Nilai Tolerance & VIF & Sig.Residu & Test Statistic \\
\hline Gaya Kepemimpinan (GK) & .530 & 1.888 & .775 & .653 \\
\hline Efektivitas Organisasi (EO) & .472 & 2.118 & .315 & .866 \\
\hline Gaya Negosiasi (GN) & .363 & 2.752 & .518 & .790 \\
\hline
\end{tabular}

Sumber: Data penelitian diolah, 2021

Uji asumsi tabel 3 menunjukkan nilai test statistic-nya variabel GK 0.653; EO 0.866 dan GN 0.790 yang kesemua variabel-variabel tersebut $>0.05$ sehingga data berdistribusi normal atau asumsi pertama terpenuhi. Asumsi kedua terpenuhi karena tolerance GK $0.530>0.10$; serta nilai VIF $1.888<10.00$ dengan demikian tidak terdapat multikolinieritas; tolerance EO $0.472>0.10$ dengan nilai VIF $2.118<$ 10.00 hal ini tidak terjadi multikolinieritas; tolerance GN $0.363>0.10$ dengan nilai VIF $2.752<10.00$ dengan demikian tidak mengalami multikolinieritas. Data yang diuji tidak mengalami heterokedasitas karena masing-masing variabel memiliki signifikan di atas 0.05 , yaitu signifikansi GK $0.775>0.05$, untuk signifikansi EO $0.315>0.05$, dan untuk signifikansi GN $0.518>0.05$. Dengan demikian persyaratan analisis terpenuhi.

\section{Analisis uji model}

Besaran kemampuan model didasarkan pada Nilai R Square (koefisien determinasi). Pengujian dengan uji $\mathrm{F}$ dimana dasar pengambilan keputusan jika Fhitung > F-tabel maka signifikan.

Tabel 4

Ringkasan Analisis Regresi Berganda

\begin{tabular}{lccc}
\hline \multicolumn{1}{c}{ R Square } & Adj. R Square & F-Hitung & Sig. F \\
\hline \multicolumn{1}{c}{ Variabel } & .760 & 28.401 & .000 \\
\hline \multicolumn{1}{c}{ Koefisien Regresi } & thitung & Sig \\
\hline Konstanta & 5,173 & 2.485 & .020 \\
Gaya Kepemimpinan (GK) & .011 & .072 & .943 \\
Efektivitas Organisasi (EO) & .172 & 1.842 & .077 \\
Gaya Negosiasi (GN) & .512 & 4.557 & .000 \\
\hline Dependen Variables: Inovasi Produk (IP) & & \\
\hline
\end{tabular}

Sumber: Data penelitian diolah, 2021 
Nilai R Square dari tabel 4 sebesar 0.785 dan adj. R Square sebesar 0,760. Nilai ini mengandung arti bahwa pengaruh GK, EO dan GN adalah sebesar 78,5\% terhadap IP.Nilai F- hitung sebesar 28.401 dan probablitas Sig. F 0.000. F-hitung $28.401>$ F-tabel 2,960 dan probabilitas Sig.F $0.000<$ taraf uji penelitian 0.05 maka signifikan dan dapat diartikan bahwa GK, EO dan GN mampu menjelaskan 78,5 variasi IP. Dengan demikian model penelitian layak untuk menjelaskan keterkaitan antar variabel melalui uji hipotesis.

\section{Analisis uji hipotesis}

Sebagai arah pengaruh ditunjukkan dengan nilai koefisien regresi melalui pengujian menggunakan uji-t. Nilai koefisien regresi yang dibentuk dalam persamaan regresi adalah $\mathrm{IP}=5.173+0.011 \mathrm{GK}+0.172 \mathrm{EO}+0.512 \mathrm{GN}$. GK memiliki koesifien regresi 0.011 , t-hitung 0.072 dan sig. 0.020 . Karena nilai sig. 0.020 lebih besar dari taraf uji penelitian 0.05 maka hipotesis pertama ditolak yang berarti bahwa GK tidak mempengaruhi IP. EO memiliki koesifien regresi 0.172, thitung 1.842 dan sig. 0.077. Karena nilai sig. 0.077 lebih besar dari taraf uji penelitian 0.05 maka hipotesis kedua ditolak yang berarti bahwa EO tidak mempengaruhi IP. GN, memiliki koesifien regresi 0.512 , t-hitung 4.557 dan sig. 0.000. Karena nilai sig. 0.000 lebih kecil dari taraf uji penelitian 0.05 maka hipotesis ketiga diterima yang berarti bahwa GN mempengaruhi IP.

\section{Kesimpulan}

Penelitian ini memberikan gambaran bahwa Gaya Kepemimpinan (GK) tidak memberikan pengaruh terhadap Inovasi Produk (IP) pada usaha UMKM fashion hijab di Kabupaten Bekasi. Tidak adanya pengaruh gaya kepemimpinan dapat di fahami mengingat skala usaha yang masih kecil sehingga kegiatan usahanya masih dilakukan oleh pemilik. Begitu pula dengan Efektivitas Organisasi (EO) dalam penelitian ini tidak memberikan pengaruh terhadap Inovasi Produk (IP) usaha fashion hijab, mengingat organisasinya masih kecil dan belum banyak melibatkan jumlah personil yang banyak. Selanjutnya Gaya Negosiasi (GN) dalam penelitian ini memiliki pengaruh terhadap Inovasi Produk (IP) usaha UMKM fashion hijab di Kabupaten Bekasi, hal ini menjadi variabel yang sangat menentukan dalam melakukan inovasi produk secara langsung dalam menjalankan kegiatan usaha sehari-hari mulai dari belanja pengadaan bahan baku, maupun membuat penawaran kontrak kerja penjualan ataupun kerjasama. Apabila pemilik usaha memiliki keilmuan, keterampilan, pengalaman dan kapasitas negosiasi yang bagus, maka dapat menunjang pengembangan inovasi produknya. 


\section{BIBLIOGRAFI}

Colovic, Ana. (2021). Leadership and business model innovation in late internationalizing SMEs. Long Range Planning, (February), 102083. Google Scholar

Dunne, Timothy C., Aaron, Joshua R., McDowell, William C., Urban, David J., \& Geho, Patrick R. (2016). The impact of leadership on small business innovativeness. Journal of Business Research, 69(11), 4876-4881. Google Scholar

Fitriati, Titi Kurnia, Purwana, Dedi, \& Buchdadi, Agung Dharmawan. (2020). The role of innovation in improving small medium enterprise (SME) performance. International Journal of Innovation, Creativity and Change, 11(2), 232-250.

Gomes, Giancarlo, Seman, Laio Oriel, Berndt, Ana Clara, \& Bogoni, Nadia. (2021). The role of entrepreneurial orientation, organizational learning capability and service innovation in organizational performance. Revista de Gestão, ahead-of$\operatorname{print}($ ahead-of-print).

Hassan, Siti Hasnah, \& Harun, Harmimi. (2016). Factors influencing fashion consciousness in hijab fashion consumption among hijabistas. Journal of Islamic Marketing, 7(4), 476-494. Google Scholar

Indrianti, Pingki, Kurniawan, Oki, \& Hassan, Faridah Hj. (2021). The Visual Analysis Of Muslimah Clothing Style In Java (15-20 th Century). El-HARAKAH (TERAKREDITASI), 23(1), 41-63. Google Scholar

Kurniati, Edy Dwi. (2014). Pengaruh Karakteristik Manajer-Pemilik Usaha, Karakteristik Organisasi Dan Lingkungan Eksternal Terhadap Kapasitas Inovasi Dan Kinerja Usaha. Jurnal Organisasi Dan Manajemen, 10(1), 124-135. Google Scholar

Memon, Mumtaz Ali, Ting, Hiram, Cheah, Jun Hwa, Thurasamy, Ramayah, Chuah, Francis, \& Cham, Tat Huei. (2020). Sample Size for Survey Research: Review and Recommendations. Journal of Applied Structural Equation Modeling, 4(2), i-xx. Google Scholar

Oke, Adegoke, Munshi, Nathasha, \& Walumbwa, Fred O. (2009). The Influence of Leadership on Innovation Processes and Activities. Organizational Dynamics, 38(1), 64-72. Google Scholar

Peleckis, Kęstutis. (2014). International Business Negotiations: Innovation, Negotiation Team, Preparation. Procedia - Social and Behavioral Sciences, 110(November), 64-73. Google Scholar

Temouri, Yama, Shen, Kathy, Pereira, Vijay, \& Xie, Xuanli. (2020). How do emerging market SMEs utilize resources in the face of environmental uncertainty? $B R Q$ Business Research Quarterly. Google Scholar 
Junedi, Adibah Yahya, Diana Sari

\section{Copyright holder:}

Junedi, Adibah Yahya, Diana Sari (2021)

First publication right:

Syntax Literate: Jurnal Ilmiah Indonesia

This article is licensed under:

(c) (i) (O) 